\title{
Kinetics of the pyrolysis of cobalt-impregnated sesame stalk biomass
}

\begin{abstract}
In this work, thermogravimetric analysis of sesame biomass samples was conducted in inert atmosphere at heating rate of $10{ }^{\circ} \mathrm{C} / \mathrm{min}$ in the temperature range $30-1000{ }^{\circ} \mathrm{C}$. Kinetic parameters were calculated applying the Coats-Redfern (CR) method. TG/DTG of sesame biomass showed that pyrolysis mainly occurred in the temperature range $205-412{ }^{\circ} \mathrm{C}$. Therefore, the biomass was thermally decomposed in the same temperature range in the presence of cobalt oxide in an indigenously made salt bath furnace. The pyrolysis oil was collected and analyzed using GC-MS. The Physicochemical properties of the oil were determined, and the results have shown that sesame biomass can be utilized as fuel if the oil obtained from it is properly upgraded to make it equivalent to commercial fuel.
\end{abstract}

Keyword: Sesame stalk; Cobalt-impregnated biomass; Pyrolysis; Kinetics; Bio-oil 